\title{
Treatment of a collapsible soil using a bentonite-cement mixture
}

https://doi.org/10.2478/sgem-2018-0042

received April 22, 2018; accepted November 10, 2018.

\begin{abstract}
The study of collapsible soils that are generally encountered in arid and semi-arid regions remains a major issue for geotechnical engineers. This experimental study, carried out on soils reconstituted in the laboratory, aims firstly to present a method of reducing the collapse potential to an acceptable level by treating them with different levels of bentonite-cement mixture while maintaining the water content and degree of compactness, thus reducing eventual risks for the structures implanted on these soils. Furthermore, a microscopic study using scanning electron microscopy was carried out to explore the microstructure of the soil in order to have an idea of the phenomena before and after treatment. The results show that treatment with a bentonite-cement mixture improves the geotechnical and mechanical characteristics, modifies the chemical composition of the soil, reduces the collapse potential and the consistency limits. The microstructural study and the X-ray energy dispersive spectroscopy analysis clearly illustrate an association of elementary particles in the soil aggregates, whereby the arrangement of these aggregates leads to the formation of a dense and stable material.
\end{abstract}

Keywords: collapsible soil; cement; bentonite; microstructure; oedometer.

\section{Introduction}

The construction of foundations on collapsible soils is considered one of the major problems of geotechnical engineering. It may be difficult, expensive or even

\footnotetext{
*Corresponding author: Soumia Bellil, Laboratory of Research in Applied Hydraulics (LRHYA), Department of Civil Engineering, University of Mustapha Ben Boulaid Batna 02, Algeria, E-mail: bellil.soumia88@gmail.com Khelifa Abbeche, Ouassila Bahloul: Laboratory of Research in Applied Hydraulics (LRHYA), Department of Civil Engineering, University of Mustapha Ben Boulaid Batna 02, Algeria
}

impossible to alter the design of railways, highways or power lines to avoid the area where such a soil is found. On the other hand, construction on natural collapsible soil without precautions can lead to dramatic and undesirable results. Human activities are undoubtedly the main cause of collapse of most of the soils.These activities include irrigation works, pipe line constructions and various works related to damaged and unrepaired hydrocarbon pipelines in the field; the poor organisation of the various sewerage networks, the non-recognition and/or repair of damaged water pipes, excessive loading on collapsible soils and any activity that increases surface moisture in soils will cause them to collapse.

Collapsible soils are metastable, unsaturated soils with a porous structure. They are often in the form of deposits. In the dry state, this type of soils can withstand high loads due to the natural cementation between the grains; however, even without the addition of loads, saturation causes the intergranular bonds to fail, thus giving a denser structure and resulting in the collapse of the soil particles. These metastable soils are generally composed of a predominant percentage of silts and a small percentage of fine elements.

Several studies [1, 2] have been carried out in the field of identification of these types of soils. Indeed, several methods have been developed in this direction, from direct to empirical methods.

Some researchers (e.g. Abbeche et al. [2] and Houston et al. [3]) have tried to make available to the technicians the tools necessary for the recognition of this type of soil and to enable them, consequently, to take the necessary precautions to secure the structures due to be implanted on this type of soil. Other researchers (e.g. Abbeche et al. [1, 2] and Bakir et al. [4]) have preferred to find a solution to the problems associated with this type of soil by proposing treatment methods that depend, on the one hand, on the depth of the soil and, on the other hand, the water retention capacity of the soil. Among these measures, one can name substitution or treatment of the soil in situ by chemical, thermal or mechanical means.

When the collapsible ground layer is not too thick (less than $4 \mathrm{~m}$ ), it is often economical to substitute it with a 
suitable soil that is compacted to a sufficient density. This operation assumes that the soil used for substitution is located close to the project and that there is enough water available for soil compaction. These two factors, which may not be available at the time of the works, especially since the areas concerned are arid or semi-arid, can have a huge impact on the cost of the project. Other measures have been proposed to deal with this problem when the soil is deep and treatment is not possible: we can cite here the piles.

The soil treatment technique was used in the late 1960s and was mainly applied to the reuse of watersensitive soils

It has allowed to achieve technically and economically major earthworks necessitated by the construction of highways without delays.

The objective of our work is to show, on the one hand, that it is possible to reduce the collapse potential to a level that presents no danger, by using the same soil excavated and replaced after treatment with a bentonite-cement mixture, while decreasing the amount of water and compaction energy and, secondly, to seek the optimum conditions for which the soil would have an acceptable collapse potential.

On the other hand, the microstructure study by scanning electron microscopy (SEM) showed that the reconstituted soil is characterised by a porous structure formed of a loose skeleton and unevenly distributed particles $[4,5,6]$. The SEM study was used to explain the effective stabilisation of soils treated with bentonitecement mixtures. This treatment was able to modify the structure of the soil by causing a rearrangement of the particles, which resulted in the genesis of a homogeneous material with formation of a stable structure with very low porosity.

\section{Materials, equipment and test procedures}

The materials used were as follows: sand ( $<2 \mathrm{~mm}$ ) from the Biskra region (Oued-Djedi river), kaolin of Tamazert (fine particles $<80 \mathrm{~mm}$ ) from El-Milia region of Jijel (Eastern Algeria), bentonite powder from the Maghnia in Tlemcen region (West Algeria) and cement CPJ 42.5 CEM II/A produced by the cement CPJ $42.5 \mathrm{CEM}$ II/A produced by the cement factory of Ain touta in Batna region (Eastern Algeria).

The tests were carried out on reconstituted soil SNT "untreated soil" (sand: $75 \%$ and kaolin: $25 \%$ ), which is

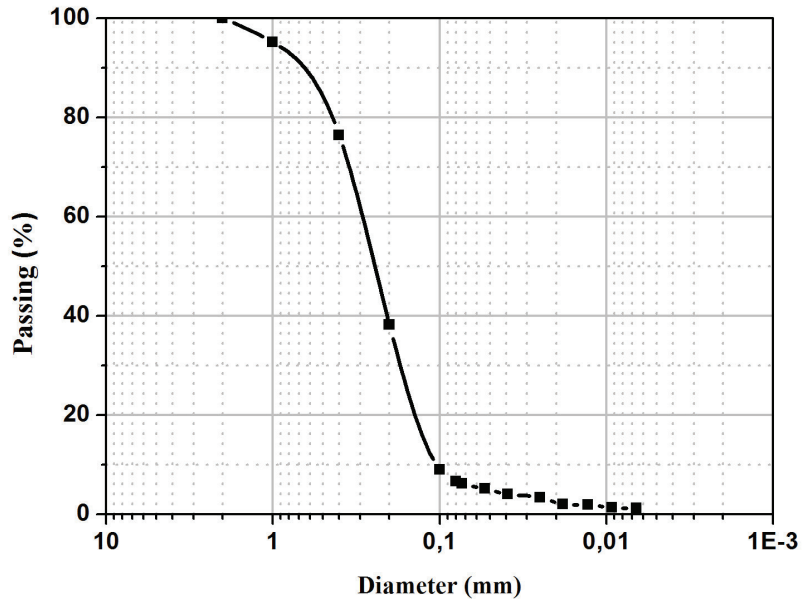

Figure 1: Granulometric curve of the collapsible soil.

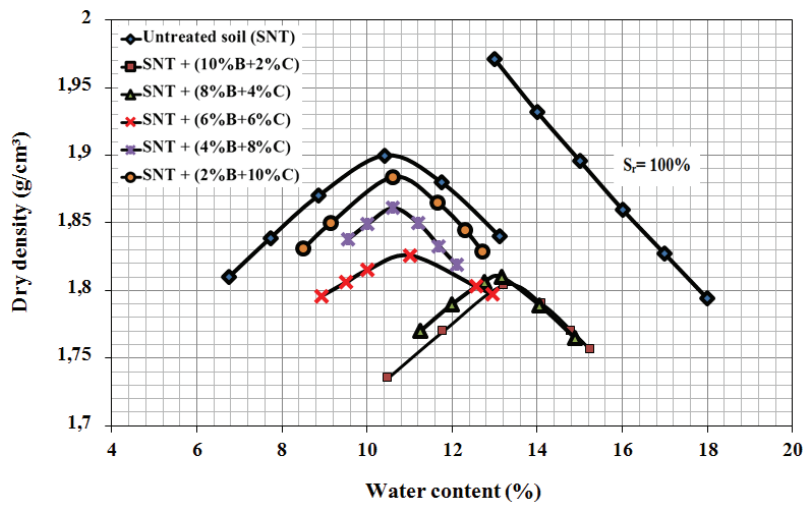

Figure 2: Compaction curves of the untreated and treated soils obtained by wetting.

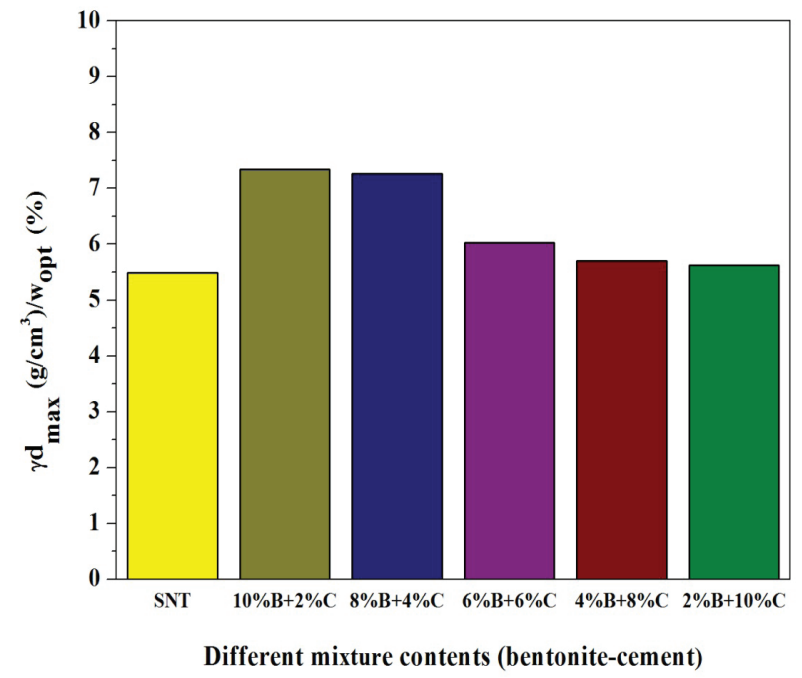

Figure 3: Variation of $\left(\frac{\gamma_{\text {tax }}}{w_{\text {op }}}\right)$ as a function of the mixture content (bentonite-cement). 
Table 1: Chemical compositions of the different soils used.

\begin{tabular}{llllll}
\hline Constituents (\%) & Sand (\%) & Kaolin (\%) & Reconstituted soil (SNT) (\%) & Bentonite (\%) & Cement (\%) \\
\hline $\mathrm{SiO}_{2}$ & 37.87 & 19.11 & 19.35 & 27.47 & 6.62 \\
$\mathrm{Al}_{2} \mathrm{O}_{3}$ & 2.31 & 17.00 & 13.48 & 10.24 & 2.27 \\
$\mathrm{Fe}_{2} \mathrm{O}_{3}$ & 1.63 & 1.15 & 1.29 & 1.71 & 2.30 \\
$\mathrm{CaO}$ & 5.41 & 0.14 & 1.86 & 1.08 & 40.30 \\
$\mathrm{MgO}$ & 0.54 & 0.28 & 0.46 & 1.55 & 0.65 \\
$\mathrm{~K}_{2} \mathrm{O}$ & 0.60 & 1.57 & 0.91 & 5.70 & 1.32 \\
\hline
\end{tabular}

Table 2: Geotechnical characteristics of different soils.

\begin{tabular}{|c|c|c|}
\hline \multirow[t]{4}{*}{ Sand $(<2 \mathrm{~mm})$} & Coefficient of uniformity, $C_{u}$ & 2.78 \\
\hline & Coefficient of curvature, $C_{c}$ & 1.05 \\
\hline & Sand equivalent, Es (\%) & 74.01 \\
\hline & Specific density, $\mathrm{G}_{\mathrm{s}}$ & 2.66 \\
\hline \multirow{4}{*}{$\begin{array}{l}\text { Kaolin } \\
(<80 \mathrm{~mm})\end{array}$} & Liquidity limit, $\mathrm{W}_{1}(\%)$ & 48.52 \\
\hline & Plasticity limit, $\mathrm{W}_{\mathrm{p}}(\%)$ & 33.82 \\
\hline & Specific density, $\mathrm{G}_{\mathrm{s}}$ & 2.70 \\
\hline & Activity, $A_{c}(\%)$ & 1.20 \\
\hline \multirow{8}{*}{$\begin{array}{l}\text { Reconstituted } \\
\text { soil (SNT) }\end{array}$} & Coefficient of uniformity, $C_{u}$ & 2.81 \\
\hline & Coefficient of curvature, $C_{c}$ & 1.05 \\
\hline & Liquidity limit, $\mathrm{W}_{1}(\%)$ & 21.64 \\
\hline & Plasticity limit, $\mathrm{W}_{\mathrm{p}}(\%)$ & 16.79 \\
\hline & Sand equivalent, $\mathrm{E}_{\mathrm{s}}(\%)$ & 65.93 \\
\hline & Specific density, $\mathrm{G}_{\mathrm{s}}$ & 2.65 \\
\hline & Dry density, $\mathrm{gd}_{\max }\left(\mathrm{g} / \mathrm{cm}^{3}\right)$ & 1.90 \\
\hline & Optimum water content, $\mathrm{w}_{\mathrm{opt}}(\%)$ & 10.42 \\
\hline \multirow{7}{*}{$\begin{array}{l}\text { Bentonite } \\
\text { (powder) }\end{array}$} & Specific surface area, $\mathrm{SSA}\left(\mathrm{m}^{2} / \mathrm{g}\right)$ & 872.00 \\
\hline & Bulk density, $\mathrm{G}_{\mathrm{s}}$ & 2.72 \\
\hline & Swelling index, $\mathrm{SI}\left(\mathrm{cm}^{3} / \mathrm{g}\right)$ & 35.00 \\
\hline & Plate water absorption ,PWA (\%) & 885.00 \\
\hline & Blue methylene value, MBV & 29.41 \\
\hline & $\mathrm{pH}$ & 9.90 \\
\hline & Plasticity index, $\mathrm{I}_{\mathrm{p}}(\%)$ & 117.54 \\
\hline Cement (CPJ & Specific weight, $\mathrm{Gs}\left(\mathrm{g} / \mathrm{cm}^{3}\right)$ & 3.04 \\
\hline \multirow[t]{4}{*}{ 42.5 (EM II/A) } & Normal consistency, $\mathrm{NC}\left(\% \mathrm{H}_{2} \mathrm{O}\right)$ & 27.44 \\
\hline & Shrinkage, $\mathrm{Wr}(\mathrm{mm} / \mathrm{m})$ & 417.00 \\
\hline & Refusal on sieve $45 \mathrm{~mm}$, RS (\%) & 12.42 \\
\hline & $\begin{array}{l}\text { Compressive strength at } 28 \text { days, } \mathrm{CR} \\
(\mathrm{MPa})\end{array}$ & 44.07 \\
\hline
\end{tabular}

Table 3: Variations of the different mixing ratios of the components (bentonite-cement).

\begin{tabular}{ll}
\hline $\begin{array}{l}\text { Untreated soil } \\
\text { (sand+kaolin) }\end{array}$ & $\begin{array}{l}\text { Soil treated with [bentonite (B)+cement } \\
(\mathrm{C})]\end{array}$ \\
\hline SNT $(75 \%+25 \%)$ & SNT $+(10 \% B+2 \% \mathrm{C})$ \\
& SNT $+(8 \% B+4 \% \mathrm{C})$ \\
& SNT $+(6 \% B+6 \% \mathrm{C})$ \\
& SNT $+(4 \% B+8 \% \mathrm{C})$ \\
& SNT $+(2 \% B+10 \% \mathrm{C})$ \\
\hline
\end{tabular}

considered as a collapsible soil according to the different collapse criteria reported by several authors (e.g. Abbeche et al. [2], Houston et al. [3] and Ayadat et al. [7]).

The granulometric curve, the Proctor curves and the geotechnical characteristics of the various materials are represented, respectively, in Figures 1,2 and 3, and the chemical compositions and the geotechnical characteristics of the soils are, respectively, shown in Tables 1 and 2.

\subsection{Testing programme}

The programme of the various tests carried out is summarised in Table 3. The parameters selected were the water content, the compaction energy and the bentonitecement mixture contents.

\subsection{Test procedures}

\subsubsection{Compressibility tests}

In order to characterise the collapse potential of the materials studied, the simple oedometer method was used. The procedure followed is that recommended by the American Society for Testing and Materials (ASTM) standards (D-5333) [8]. The samples were made from a mixture of basic materials (sand and clay), dried in an oven at a temperature of $105^{\circ} \mathrm{C}$ and homogenised. After homogenisation, the material was brought to the desired water content by adding the required amount of distilled water.

After preparation of a well-homogenised mix, it was poured into the cylindrical odometer kit and compacted directly in the oedometer ring using the laboratorydesigned standardised compaction hammer [5], with a certain compaction energy (number of strokes per layer). The specimen was then flashed at the upper edge of the ring, using a rigid blade, to obtain a flat surface. After 
weighing the test piece, it was put back into the oedometer mould, on which the compressibility test described by Jennings and Knight was performed [9].

The test consists of loading the soil progressively, starting from a known water content and an initial specific weight, up to $200 \mathrm{kPa}$, the stress at which the flooding of the sample is carried out. The axial deformation of the sample is measured by a dial gauge having an accuracy of the order of $1 \mathrm{~mm}$. During flooding, the compaction of the specimen is recorded at different time intervals.

\subsubsection{Shear tests}

Samples were prepared in the same manner as for oedometer tests samples and according to the French standard NF P 94-071-1. For each test, three normal stresses were used (100, 200 and $300 \mathrm{kPa}$ ).

\section{Results and discussion}

\subsection{Study of the influence of compaction energy on the collapse potential $C_{p}$}

The decrease in collapse potential is more marked than the decrease in compaction energy, and it increases with moisture content for values of $\mathrm{w}_{0}=4 \%, 6 \%$ and $8 \%$. These results are in agreement with the findings of some authors (e.g. Abbeche et al. [2], Bahloul et al. [5] and Ayadat and Gherabli [10]).

It is also noted that there is an increase in the collapse potential for a compaction energy corresponding to 30 strokes for the soil studied, which has a loose structure with many voids, facilitating the migration of fine particles from one level to another [5].

Reciprocally, compacting at 70 strokes makes the soil relatively dense and the destruction of intergranular bonds, and the movement of the fine particles becomes slow [11].

\subsection{Influence of water content on the collapse potential $C_{p}$}

Table 5 also shows that the collapse potential $C_{p}$ decreases when the water content increases. These results are consistent with those obtained by Abbeche et al. [1, 2] and Phanikumar [12]. Thus, artificially prepared soil behaves similarly to natural soils.
Table 4: Geotechnical characteristics of soils.

\begin{tabular}{lllll}
\hline Soils & $\mathbf{W}_{\mathbf{1}}(\%)$ & $\mathbf{W}_{\mathrm{p}}(\%)$ & $\mathbf{W}_{\text {opt }}(\%)$ & $\mathbf{g d}_{\max }\left(\mathbf{g} / \mathbf{c m}^{3}\right)$ \\
\hline SNT & 21.64 & 16.79 & 10.425 & 1.900 \\
SNT+ (10\%B+2\%C) & 32.49 & 24.59 & 13.235 & 1.804 \\
SNT+ (8\%B+4\%C) & 32.20 & 25.49 & 13.154 & 1.810 \\
SNT+ (6\%B+6\%C) & 32.05 & 25.61 & 11.015 & 1.826 \\
SNT+ (4\%B+8\%C) & 25.32 & 21.12 & 10.606 & 1.861 \\
SNT+ (2\%B+10\%C) & 23.32 & 19.50 & 10.602 & 1.884 \\
\hline
\end{tabular}

\subsection{Influence of bentonite-cement treatment on the Atterberg limits of the treated soil}

According to Table 4, the liquidity limit of the treated soil increases with respect to the control soil and the limit of plasticity, which justifies the effect of the treatment on the consistency limits.

Thus, the efficiency of these treatments illustrates the phenomenon of adsorption of bentonite on the one hand and the hardening of the cement on the other hand. Increasing the amount of cement requires more water to dissociate the portlandite and to produce $\mathrm{Ca}^{+2}$ cations required for cation exchange reactions [13, 14]. The reduction of bentonite is due to the fact that the addition of cement creates the aggregation of the particles and thus generates a larger volume. This leads to a change in the pore size distribution [15].

The limit of plasticity of montmorillonite increases with the addition of cement up to $8 \%$ and then begins to decrease. It is concluded that adding the treatment to a control soil increases the consistency limit $[16,17]$.

\subsection{Effect of bentonite-cement mixture on the collapse potential of treated soil}

Based on the classification of Jennings and Knight, there is a risk of collapse if $C_{p}$ is $>1$. Based on this classification in Table 6, the results of the collapse potentials obtained for the untreated soil (SNT) range from $2.239 \%$ to $8.350 \%$, which corresponds to the categories "moderate disorder to disorder". These results clearly show that $C_{\mathrm{P}}$ decreases every time the compaction energy increases.

The influence of bentonite-cement mixture is shown by lower values of the collapse potential relative to the control soil, ranging from $0.220 \%$ to $6.796 \%$. According to the Jennings and Knight classification, these soils can be classified in the case of "no problem". 
Table 5: Variation of the collapse potential $C_{p}$ of the treated and untreated soils.

\begin{tabular}{|c|c|c|c|c|c|c|c|c|c|c|}
\hline \multirow[t]{2}{*}{ Type of soils } & \multirow{2}{*}{$\begin{array}{l}\text { Water content } \\
(\%) \\
\text { Number of } \\
\text { strokes, } E_{c}\end{array}$} & \multicolumn{3}{|l|}{4} & \multicolumn{3}{|l|}{6} & \multicolumn{3}{|l|}{8} \\
\hline & & 30 & 50 & 70 & 30 & 50 & 70 & 30 & 50 & 70 \\
\hline \multirow[t]{3}{*}{ SNT } & $e_{0}$ & 0.504 & 0.465 & 0.429 & 0.500 & 0.451 & 0.403 & 0.497 & 0.446 & 0.396 \\
\hline & $\mathrm{S}_{\mathrm{r}}(\%)$ & 21.328 & 23.767 & 26.767 & 31.800 & 35.255 & 39.454 & 42.063 & 45.591 & 49.417 \\
\hline & $C_{p}(\%)$ & 8.350 & 5.232 & 3.578 & 8.166 & 5.105 & 3.104 & 7.712 & 4.390 & 2.239 \\
\hline \multirow[t]{3}{*}{ SNT+ $(10 \% B+2 \% C)$} & $\mathbf{e}_{0}$ & 0.491 & 0.459 & 0.426 & 0.487 & 0.444 & 0.400 & 0.486 & 0.440 & 0.393 \\
\hline & $S_{r}(\%)$ & 18.271 & 20.181 & 22.595 & 27.351 & 30.000 & 33.300 & 36.171 & 38.700 & 41.700 \\
\hline & $C_{p}(\%)$ & 6.796 & 4.722 & 2.153 & 6.392 & 4.239 & 2.000 & 5.750 & 3.818 & 1.753 \\
\hline \multirow[t]{3}{*}{$\mathrm{SNT}+(8 \% \mathrm{~B}+4 \% \mathrm{C})$} & $e_{0}$ & 0.469 & 0.447 & 0.419 & 0.467 & 0.428 & 0.396 & 0.459 & 0.425 & 0.389 \\
\hline & $\mathbf{S}_{r}(\%)$ & 19.172 & 20.705 & 22.622 & 28.265 & 30.841 & 33.334 & 37.526 & 39.373 & 42.004 \\
\hline & $C_{p}(\%)$ & 2.393 & 1.539 & 1.054 & 2.129 & 1.519 & 1.047 & 2.097 & 1.502 & 0.565 \\
\hline \multirow[t]{3}{*}{$\mathrm{SNT}+(6 \% \mathrm{~B}+6 \% \mathrm{C})$} & $\mathbf{e}_{0}$ & 0.480 & 0.453 & 0.422 & 0.477 & 0.436 & 0.398 & 0.473 & 0.433 & 0.391 \\
\hline & $\mathrm{S}_{\mathrm{r}}(\%)$ & 18.700 & 20.415 & 22.608 & 27.800 & 30.412 & 33.316 & 36.834 & 39.028 & 41.895 \\
\hline & $C_{p}(\%)$ & 2.764 & 2.456 & 1.439 & 2.362 & 1.591 & 1.432 & 2.074 & 1.464 & 0.916 \\
\hline \multirow[t]{3}{*}{ SNT+(4\%B+8\%C) } & $\mathbf{e}_{0}$ & 0.451 & 0.437 & 0.410 & 0.446 & 0.413 & 0.392 & 0.437 & 0.412 & 0.384 \\
\hline & $\mathbf{S}_{\mathrm{r}}(\%)$ & 20.411 & 21.650 & 23.230 & 30.000 & 32.400 & 34.132 & 39.556 & 40.823 & 43.512 \\
\hline & $C_{p}(\%)$ & 1.500 & 0.706 & 0.662 & 1.659 & 0.495 & 0.462 & 1.102 & 0.209 & 0.220 \\
\hline \multirow[t]{3}{*}{ SNT+(2\%B+10\%C) } & $e_{0}$ & 0.460 & 0.442 & 0.415 & 0.457 & 0.420 & 0.394 & 0.447 & 0.418 & 0.386 \\
\hline & $\mathrm{S}_{\mathrm{r}}(\%)$ & 19.686 & 21.052 & 22.800 & 28.884 & 31.428 & 33.502 & 38.260 & 39.819 & 42.409 \\
\hline & $C_{p}(\%)$ & 1.559 & 0.789 & 0.797 & 1.754 & 0.560 & 0.516 & 1.433 & 0.578 & 0.336 \\
\hline
\end{tabular}

Table 6: Values of the collapse potentials.

\begin{tabular}{ll}
\hline $\mathbf{C}_{\mathrm{p}}(\%)$ & Susceptibility to collapse \\
\hline $0-1$ & No problem \\
$1-5$ & Moderate trouble \\
$5-10$ & Trouble \\
$10-20$ & Severe trouble \\
$>20$ & Very severe trouble \\
\hline
\end{tabular}

However, the various degrees of the treatments make it possible to observe that the collapse potential $\mathrm{C}_{\mathrm{p}}$ decreases, which shows the effectiveness of this treatment.

\section{Effect of the bentonite-cement mixture on the mechanical characteristics of the soil}

The results obtained through the shear tests are represented in the form of histograms, showing the following patterns:

According to the previous results in Fig. 4 a reduction in the shear strength of the control soil (SNT) is clearly

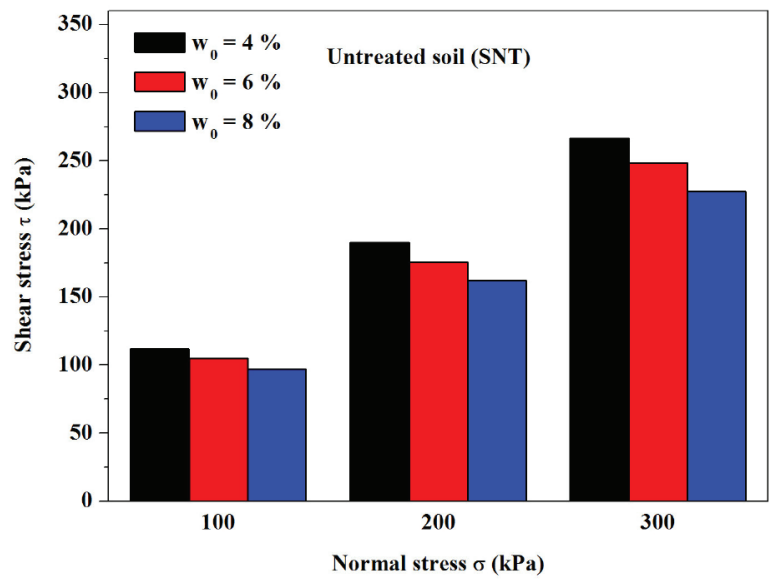

Figure 4: Variations of tangential stresses of control soil (SNT).

observed when the water content is increased, regardless of the compression stress applied. This is because the presence of water favours the sliding of the grains, which makes it possible for them to move more easily with respect to one another [18].

Figure 5 shows that the shear stress of the treated and untreated soils increases with the normal stress applied to the different mixtures and for different water contents. 

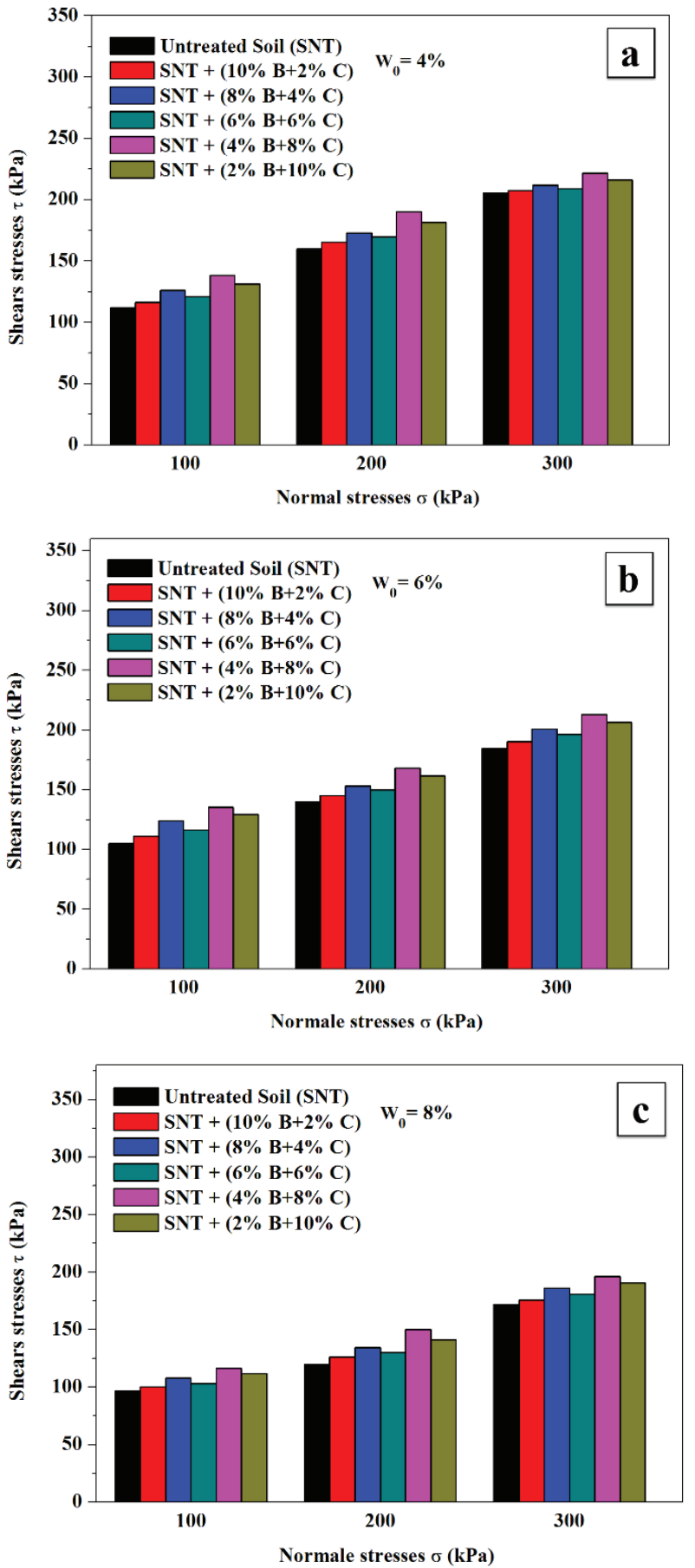

Figure 5: Variations of the tangential stresses of the various mixtures before and after treatment.

However, the increase in the normal stress leads to entanglement and significant friction between the grains.

From Figures $5 \mathrm{a}, \mathrm{b}$ and $\mathrm{c}$, it is observed that the resistance of the treated soil to shear increases with increase in the amount of bentonite-cement mixture,
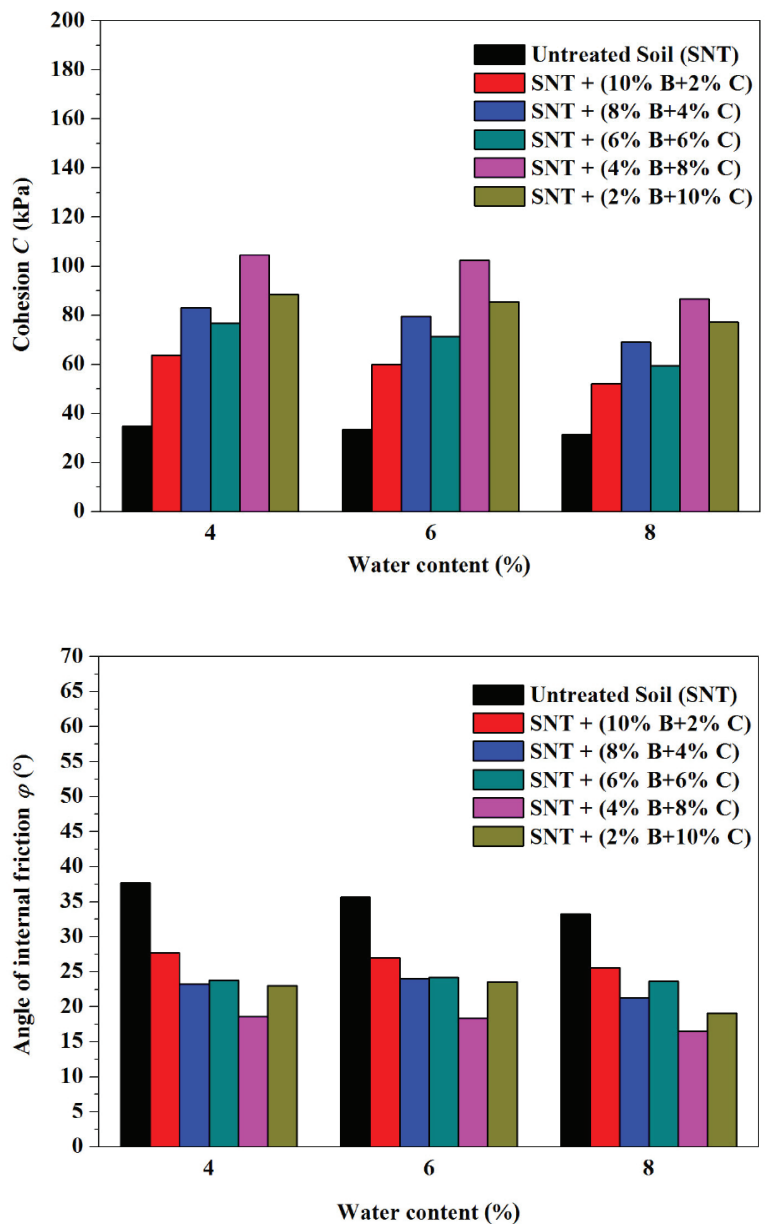

Figure 6: Evolution of the cohesion $(C)$ and the internal friction angle $(\varphi)$ in the different mixtures.

and this is so for any applied compressive stress. This is because the treatment increases the cementation at the level of the intergranular contacts. It is observed that the cohesion increases and the angle of internal friction decreases relatively.

This behaviour can be attributed to the effect of the cementing action of the cement, while the hydrate crystals give a particularly dense crystalline structure and - intermingled as bentonite - accelerate the hydration of the cement due to their high activity and suppress the sedimentation of cement while increasing the setting time, thus giving a homogeneous and stable structure, as shown in Table 7 [18].

In addition, Fig. 6 illustrates a reduction in friction. This can be explained by the growth of the clay fraction elements and the increase in the mixture content of the treatment, which results in the lubricity of the clay particles. Lubrication is due to the mobility of the absorbed layer. 
Table 7: Geotechnical characteristics of the different mixtures.

\begin{tabular}{llllllll}
\hline Soil types & SNT & $\begin{array}{l}\text { SNT+ } \\
(10 \% B+2 \% C)\end{array}$ & SNT+ (8\%B+4\%C) & SNT+ (6\%B+6\%C) & SNT+ (4\%B+8\%C) & SNT+ (2\%B+10\%C) \\
\hline $\mathbf{w}_{0}=$ & $C(\mathrm{kPa})$ & 34.76 & 63.70 & 83.09 & 76.71 & 104.54 & 88.51 \\
$\mathbf{4} \%$ & $\boldsymbol{\varphi}\left({ }^{\circ}\right)$ & 37.68 & 27.74 & 23.22 & 23.79 & 18.60 & 23.02 \\
$\mathbf{w}_{\mathbf{0}}=$ & $\boldsymbol{C}(\mathrm{kPa})$ & 33.33 & 60.00 & 79.37 & 71.45 & 102.29 & 85.53 \\
$\mathbf{6 \%}$ & $\boldsymbol{\varphi}\left({ }^{\circ}\right)$ & 35.66 & 27.02 & 24.05 & 24.20 & 18.37 & 23.54 \\
$\mathbf{w}_{\mathbf{0}}=$ & $\boldsymbol{C}(\mathrm{kPa})$ & 31.36 & 52.00 & 69.11 & 59.54 & 86.56 & 77.21 \\
$\mathbf{8} \%$ & $\boldsymbol{\varphi}\left({ }^{\circ}\right)$ & 33.20 & 25.64 & 21.25 & 23.63 & 16.51 & 19.08 \\
\hline
\end{tabular}
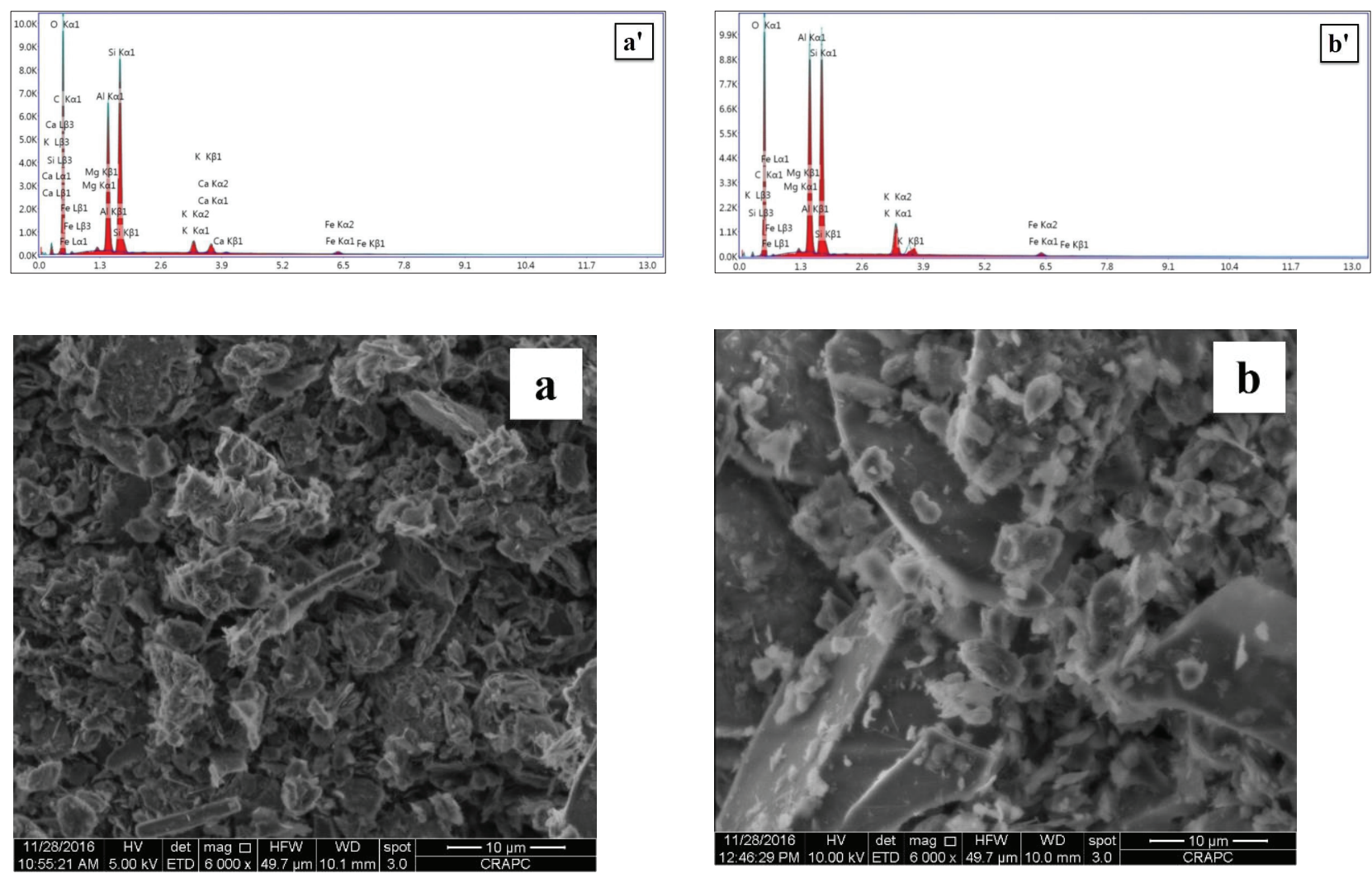

Figure 7: SEM and EDS analyses of control soil (SNT) without treatment.

\section{Microstructure analyses using SEM and X-ray energy dispersive spectroscopy (EDS) scan}

\subsection{Control soil (SNT) microanalysis}

A general view of Fig. 7a shows an open structure, rather loose, with appearance of pores of large size (4.0-8.0 $\mathrm{mm}$ ) represented in a black background, explained as the destroyed kernel bonds, which makes the SNT correspond to poor compaction of the sample (30 blows). No orientation was observed between the kaolinite crystallites and quartz crystals. This type of soil microstructure reconstituted in the laboratory has been reported by various authors $[4,5$, $6]$.

The SEM image in Fig. 7b shows a dense and impermeable structure (70 blows) with respect to Fig. $7 \mathrm{a}$, with a distribution of the elementary particles on all the pores $(0.2-0.5 \mathrm{~mm})$. There is good adhesion between the crystallites of kaolinite and the crystals of quartz, without limitation; hence, the aggregates are constituted by the agglomeration of clay minerals with strong connectivities. 

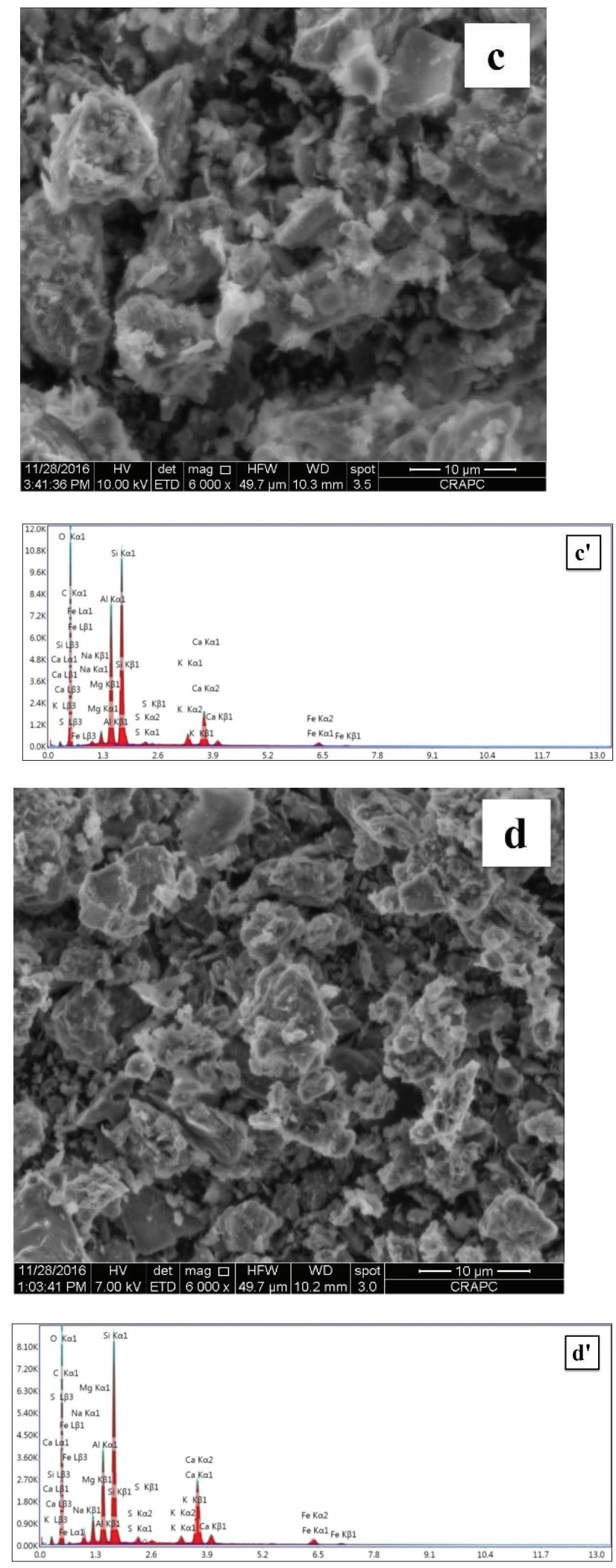

Figure 8. SEM and EDS analyses of the soil treated with various dosages of $(10 \%$ bentonite $+2 \%$ cement $)$
The EDS analysis shows that the sample is mainly a clay constituted of quartz silicates (Si), kaolinite (Al), iron oxide $(\mathrm{Fe})$, carbonates $(\mathrm{C})$, muscovite $\left(\mathrm{KAl}_{2}\right)$ and feldspar (K). These elements are attributed by the sand mixture, which is a quartzous discharge with kaolin, a high content of quartz (45.0\%) and pure kaolinite $(23.0 \%)$.

\subsection{Microanalysis of treated soil}

Figures $8 \mathrm{c}$ and $\mathrm{d}$ show a different structure compared to that of untreated soil (SNT). This difference can be attributed to the high bentonite percentage $(10 \%)$ in a lower cement content (2\%), causing the reaction between $\mathrm{CaO}$ and carbon dioxide from air, which leads to the formation of calcite, which precipitates as crystals. The formed calcite crystals are very fragile cementing binders and, therefore, weakly connect the soil particles.

Under the effect of shear, the electrostatic bonds between the cement grains are broken, resulting in a decrease in the apparent viscosity of the clay matrix [19, 20]. Therefore, the potential collapse $C_{p}$ decreased by just $2 \%$ compared to the control soil.

The high percentage of bentonite in the structure shows that the interlayer connections are very low, and these soils have the property of binding water molecules between two adjacent layers; this is explained as water enters the interior of the particles and is organised in monomolecular layers (water retention capacity). However, we obtain a clay structure that has a very large pore size [15], in other words, the shape and distribution of the porous spaces depend on its swelling character and also the shape of the gels at very low concentrations (pore fluid) [21].

The absorption of water between the parallel sheets will then limit and prevent contact between the cement grains and water, thus inhibiting the hydration of cement [17].

A quantitative analysis by means of EDS of the treated sample showed the presence of the majority of elements constituting bentonite, such as montmorillonite, quartz, mica, feldspar and calcite (Fig. 8d').

Generally, it is noted that the soil treated with (8\% bentonite $+4 \%$ cement) and ( $6 \%$ bentonite $+6 \%$ cement) has a slightly compacted structure with a lower porosity, relative to the soil treated with $(10 \%$ bentonite $+2 \%$ cement) (Figures 9e and f).

The use of bentonite in a cement complex delays its setting, reduces its strength but gives a more or less homogeneous structure. Moreover, the silicate 

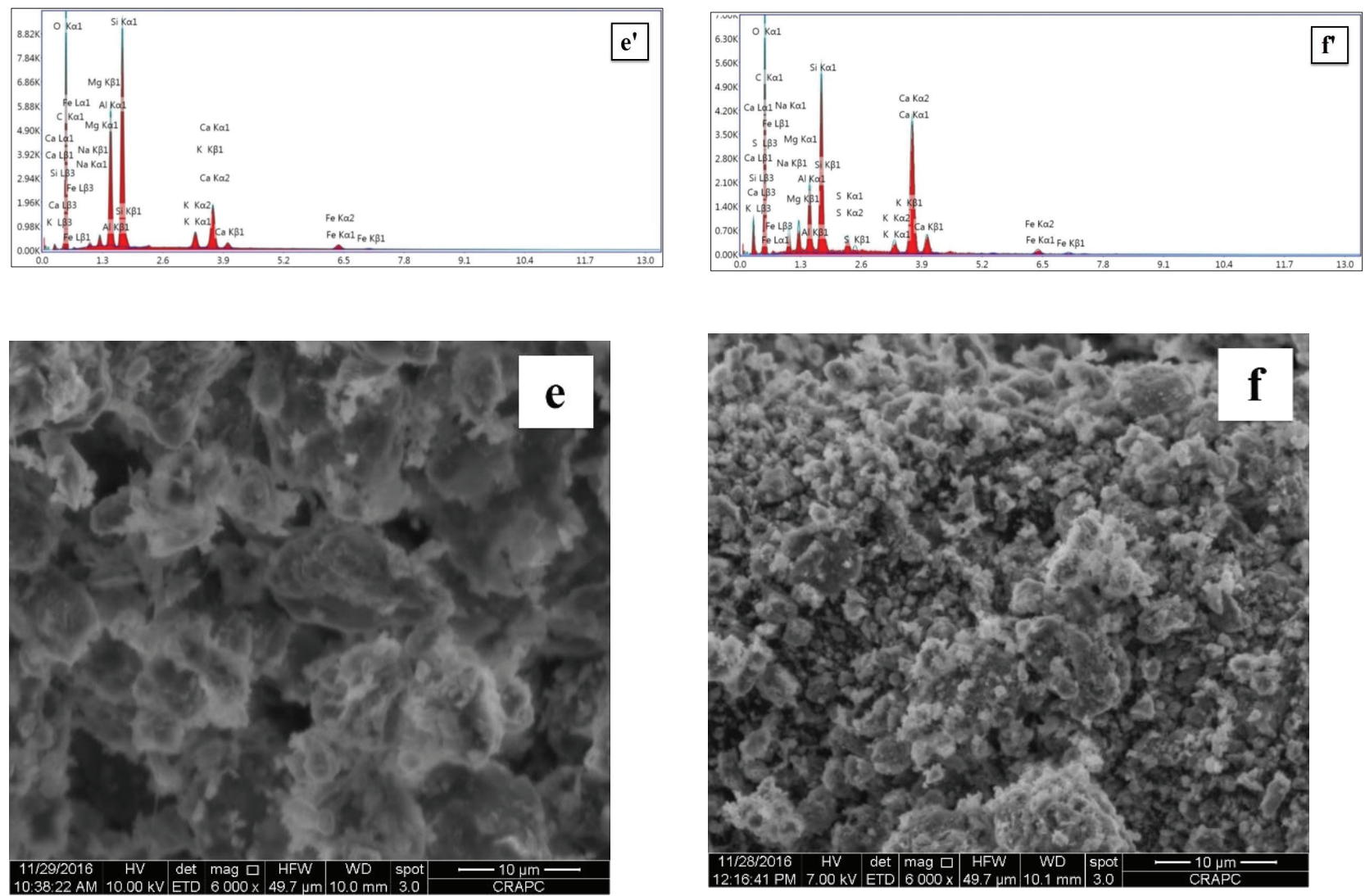

Figure 9: SEM and EDS analyses of soil treated with ( $8 \%$ bentonite $+4 \%$ cement) and ( $6 \%$ bentonite $+6 \%$ cement).

accelerates the setting but leads to a clotted structure $[15,22]$. Furthermore, bentonite prevents the contribution of crystals of ettringite in an undesirable way to the argillaceous matrix, thus an improvement of the mechanical properties is developed slightly [16].

After the equilibrium is obtained on treatment of the soil with the (bentonite-cement) mixture, it is clear that the elements have been rearranged by creating a densification of the soil compared to other treatments. Additionally, the size of the intra-aggregate pores has been changed so that the effect of the cement dosage is high compared to the effect due to the high level of bentonite, which gives a moderately dense structure.

These observations demonstrate the effect of decreasing the collapse potential. The EDS analysis shows that the materials are very rich in $\mathrm{SiO}_{2}$ and $\mathrm{Al}_{2} \mathrm{O}_{3}$. Their mass contents in the carbonates (C) are quite high and they precipitate in the crystalline form.

The addition of a high cement content and a lower percentage of bentonite to a control soil (Figures 10g and h) results in an agglomerated structure with intimately bonded grains, which decrease the pore size [16]. This is explained by the fact that flocculation is followed by pozzolanic reactions, which lead to the creation of calcium-silicate-hydrate (CSH) and calcium-aluminosilicate-hydrate (CASH), which in turn fill these pores and form solid bridges [23]. Furthermore, the montmorillonite accelerates the cement hydration due to its high activity, thus suppressing the sedimentation and increasing the setting time.

It is also observed that particle agglomerates are developed; we notice that the hydroxide was clearly shown in Figure 10g' and agglomeration seems to be the consequence of flocculation, which results from the cation exchange reaction between the charge-compensating cations of the sample and the $\mathrm{Ca}^{+2}$ cations that are derived from the dissociation of portlandite in an aqueous medium. A compound formed during hydration of the cement and particles consisting essentially of calcium and sulphur were observed (Figure 10h').

The cement prevents the penetration of water into the clay particles to stabilise the gel of the bentonite formed in the water, where hydration is rapid, generates a large amount of heat and leads to the formation of calcium hydroxide $(\mathrm{CH})$ [24]. At the same time that this reaction proceeds, some of the $\mathrm{CH}$ will dissolve in the pore water 

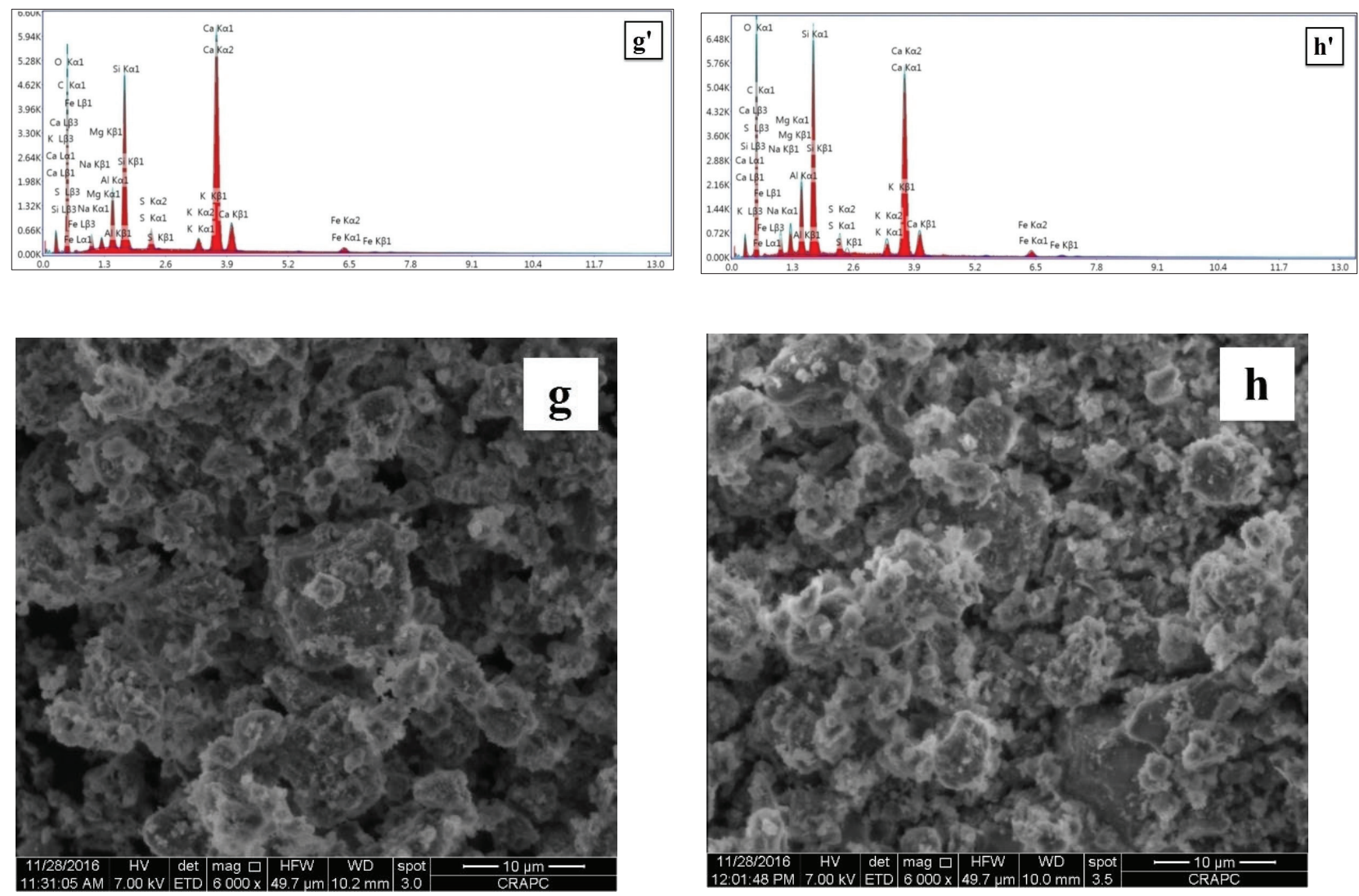

Figure 10: SEM and EDS analyses of soil treated with ( $4 \%$ bentonite $+8 \%$ cement) and ( $2 \%$ bentonite $+10 \%$ cement).

and will be adsorbed by the soil particles. Ionic exchanges, in particular, the replacement of sodium ions $\left(\mathrm{Na}^{+}\right)$in the soil by calcium ions $\left(\mathrm{Ca}^{+2}\right)$ (Khemissa et al. 2014)[23], will result in a pore size that is quite limited [25].

The EDS revealed a high $\mathrm{CaO}$ content (26.09\%) with crystalline phases such as quartz, kaolinite, montmorillonite, silicate, feldspar, calcite and carbonates.

\section{Conclusion}

The present work is a contribution to the stabilisation problem of collapsible soils, which is achieved by the addition of a bentonite-cement mixture at different percentages. The results obtained clearly show the effect of this stabiliser (bentonite-cement) on the physical and mechanical characteristics of the collapsible soil studied.

The consistency tests show that the samples treated with the bentonite-cement mixture show an increase in consistency when the percentage of bentonite increases from $2 \%$ to $10 \%$ on the one hand and a decrease in consistency with the decrease of the percentage of cement from $10 \%$ to $2 \%$ on the other hand.
The bentonite-cement mixture modifies the compaction characteristics. The dry density decreases due to the effect of the cement, which leads to an agglomeration of the soil particles, while an increase in the optimum water content occurs due to the high bentonite content, which increases water retention due to the presence of montmorillonite leaflets. It is also noted that, for the treated samples, the cohesion increases and the angle of internal friction decreases. This behaviour can be attributed to the effect of the bentonite-cement mixture.

According to the compressibility tests, the collapse potential $\mathrm{C}_{\mathrm{p}}$ decreases when the water content and the compaction energy increase. It is also found that the best optimum reduction is obtained for contents of bentonite and cement equalling $4 \%$ and $8 \%$, respectively.

Microanalysis by means of SEM revealed that untreated samples are characterised by a loose structure with large pore spaces, compared to the treated samples, which have a dense structure with particle rearrangement.

Accordingly, in a bentonite-cement mixture, the sodium $\left(\mathrm{Na}^{+}\right)$and calcium $\left(\mathrm{Ca}^{+2}\right)$ ions captured by the clay 
particles to form cementitious products lead to a decrease in porosity, which results in a rigid and stable structure.

\section{References}

[1] Abbeche, K., Ayadat, T., Lahmadi, A. (2009). Treatment of a soil with sudden collapse by lime. Seminar International Innovation and Valorization in Civil Engineering, 164-168.

[2] Abbeche, K., Bahloul, O., Ayadat, T. Bahloul, A. (2010). Treatment of collapsible soils by salts using the double consolidation method. In: Experimental and Applied Modeling of Unsaturated Soils, Proceedings of Geoshanghai, Shanghai, Chine, doi: 10 1061/41103 (396)10.

[3] Houston, S.L., Houston, W.N. and Zapata, C.E. (2001). Geotechnical engineering practice for collapsible soils. Geotechnical and Geological Engineering, 19(3/4), 333-355.

[4] Bakir, N., Abbeche, K., Panczer, G. (2017). Experimental study of the effect of the glass fibers on reducing collapse of collapsible soil. Geomechanics and Engineering, 12(1), 71-83.

[5] Bahloul, O., Abbeche, K., Bahloul, A., Halitim, A. (2014). Effect of sodium chloride on the wetting induced collapse strain of soils. MJCE, 26, 119-135.

[6] Bahloul, O., Abbeche, K., Bahloul, A. (2016). Study of the microstructure of collapsible soil treated with the potassium chloride. Journal of Applied Engineering Science and Technology, 2(1), 39-42.

[7] Ayadat, T., Belouahri, B., Ait Ammar, R. (1998). The migration of fine particles as an explanatory approach to the mechanism of soil collapse. French Revue of Géotechnique, no. 83, 73-81.

[8] ASTM, D5333. (1996). Standard Test Method for Measurement of Collapse Potential of Soils. American Society for Testing and Materials, West Conshohocken, PA, USA.

[9] Jennings, J.E., Knight, K. (1975). A guide to construction on or with materials exhibiting additional settlement due to collapse of grain structure. In Proceedings of 6th, Regional Conference for Africa on SMFE, Durban, South Africa, pp. 99-105.

[10] Ayadat, T., Gherabli, H. (1995). Treatment of a ground that can be collapsed with cement CPA 32.5. Annals TIBTP, 34-43.

[11] Benchouk, A. (2014). Hydromechanical behavior of compact fine soils in the vicinity of saturation. Ph.D. Dissertation, University of Tlemcen, Algeria.

[12] Phanikumar, B.R., Raghav, R., Bhargav, K. (2016). Collapse behaviour of a lateritic soil. Geomechanics and Geoengineering: An International Journal, 11(2), 119-124.

[13] Suksun, H., Runglawan, R., Avirut, C., Yuttana, R., Apichat, S. (2010). Analysis of strength development in cement-stabilized silty clay from microstructural considerations. Construction and Building Materials, 24, 2011-2021.

[14] Behzad, F., Thu, M.L., Behnam, F., Khabbaz, H. (2013). Shrinkage properties of soft clay treated with cement and geofibers. Geotechnical and Geological Engineering, 31, 14211435.

[15] Katsioti, M., Katsiotis, N., Rouni, G., Bakirtzis, D., Loizidou, M. (2008). The effect of bentonite/cement mortar for the stabilization/solidification of sewage sludge containing heavy metals. Cement and Concrete Composites, 30, 1013-1019.
[16] Castro-Fresno, D., Movilla-Quesada, D., Vega-Zamanillo, A., Calzada-Pérez, M.A. (2011). Lime stabilization of bentonite sludge from tunnel boring. Applied Clay Science, 51, 250-257.

[17] Ata, A.A., Salem, T.N., Elkhawas, N.M. (2015). Properties of soilbentonite-cement bypass mixture for cutoff walls. Construction and Building Materials, 93, 950-956.

[18] Fattah, M.Y., Al-Ani, M., Al-Lamy, T.A. (2013). Studying collapse potential of gypseous soil treated by grouting. The Japanese Geotechnical Society.

[19] Szymkiewicz, F. (2011). Evaluation of the mechanical properties of a cement-treated soil. Ph.D. Dissertation, University of ParisEast, Paris, France.

[20] Sujit Kumar, D., Monowar, H. (2012). Lime stabilization of soils: reappraisal. Journal of Materials in Civil Engineering, 24, 707.

[21] Le Kouby, A., Duc, M., Marino-Paredes, J., Fanelli, S. (2016). Multi-scale approach of clay soil treatment by the deep mixing method. National Days of Geotechnical Engineering and Geology.

[22] Sasanian, S., Newson, T.A. (2014). Basic parameters governing the behaviour of cement-treated clays. Soils and Foundations, 54, 209-224.

[23] Khemissa, M., Mahamedi, A.K. (2014). Cement and lime mixture stabilization of an expansive overconsolidated clay. Applied Clay Science, 95, 104-110.

[24] Kitazume, M. (2005). State of practice report: field and laboratory investigation, properties of binders and stabilised soils. In: Deep Mixing. Edited by B. Rydell, G. Westberg, K.R. Massarsch. Stockholm, pp. 660-684.

[25] Cokca, E. (2001). Use of class: C fly ash for the stabilization of an expansive soil. Journal of Geotechnical and Geoenvironmental Engineering, 127(7), 568-573. 